\title{
Identification of Hard Tick Species Affecting Camels (Camelus Dromedarius) and Their Seasonal Abundance in Najran, Saudi Arabia
}

\author{
M. H. Abdally ${ }^{1}$
}

\begin{abstract}
A study was conducted to identify the species of ticks infesting camels (Camelus dromedarius) and their seasonal population dynamics in Najran, South Saudi Arabia. Collection and identification of the ticks were undertaken at 1 year period from January 2005to December 2005. On each occasion, all the visible ticks were collected from the body of each camel and the surrounding ground. The most abundant species of ticks found on the camels at the study areas were Hyalomma anatolicum anatolicum, $\boldsymbol{H}$. $\boldsymbol{a}$. excavatum, $\boldsymbol{H}$. dromedari, $\boldsymbol{H}$. impeltatum, $\boldsymbol{H}$. schulzei, $\boldsymbol{H}$. erythraeum, $H$. marginatum rufipes, $H$. truncatum, Amblyomma t. gema and A. $t$. varigatum. The average tick load per camel was higher during rainy months (more than 40 ticks) than during dry months (less than 15 ticks). The study concluded that a strategy should intended to control the tick infestation of camels in Najran and it should take into account the identified tick species and their seasonal abundance.
\end{abstract}

Keywords:Camel,dromedary,Hyalomma,Amblyomma, prevalence, season, Najran

\section{INTRODUCTION}

Najran Province is located at the south of Saudi Arabia. It is very hot in summer and much cool in Winter (Global Arabic Encyclopedia, 2008).This harsh condition is generally suitable to camels and for this reason they are the most important animal resource in Najran as in all Saudi Arabia. Only the Arabian camels (Camelus dromedarius) are reared in Najran and they play a very important role in the life of people ( as Arabian ), they are used as meat, dairy, sports and transportation animals beside using as stored wealth for the future harsh times. In fact camels like other animals are affected with a number of diseases and parasites (AlZubaidy, 1995).The external parasites of camels include ticks, mites, and other parasitic arthropods e.g. myiasis flies (Al-Zubaidy,1995;Soulsby, 1986). Generally it is well known that ticks are a major constraint on the world's livestock industry (Zeleke and Bekele, 2004). They exert a major hindrance to improving animal production in the tropical and subtropical regions of the world by transmitting devastating and often fatal livestock diseases, causing blood loss, damage to hides and udder, and paralysis (Dalgliesh et al., 1990). Ticks are classified into two families. The family Ixodidae or hard ticks and Argasidae or soft ticks (Soulsby, 1986; Urquhart et al. 1987). In this study attention is only paid to the hard ticks infesting camels because they are the most common external parasites affecting camels and other livestock in Saudi Arabia and other Arab countries (Al-Khalifa et. al., 2007; Al- Zubaidy; 1995; Banaja and Roshdy, 1978; Hoogstraal et. al., 1981).

Ticks can transmit pathologic agents to a host mechanically or biologically which require that the infectious organism goes through some sort of development or maturation within the vector. The organisms can be transferred either transstadially (stage to stage) or transovarially (from female to offspring via the egg).Transstadial transmission usually occurs in three-host ticks. While transovarian transmission is the most common in one host ticks. Some ticks employ all of the above methods of transmission. Heavy tick infestations are often responsible for considerable morbidity and mortality in both domestic and wild camel species (Zeleke and Bekele; 2004). The most important ruminant blood parasites transmitted by ticks are Theileria spp., Babesia spp. and Anaplasma spp. (Soulsby, 1986; Urquhart et al., 1987; Walker, 1994). Anaplasma marginale and Theileria camelus parasites were reported to be found in camels ( Soulsby ; 1986 ), However Babesia motasi and B. ovis are parasites of sheep and goats (Urquhart et al., 1987) all are transmitted by species of hard ticks which are infesting camels . According to a study performed by Gupta and Kumar(1994) it was found that hard ticks of Hyalomma dromedarii were the most abundant species infesting Indian dromedaries (90 \%). However, more than 13 species and subspecies were reported to infest camels among other livestocks in Saudi Arabia ( Al-Khalifa et. al., 2007; Banaja and roshdy,1978; Banaja and Ghandour, 1994 ; Banaja et. al.,1980 ; Hoogstraalet, al.,1981 ). In fact these ticks are well adapted to harsh desert conditions (Morel; 1989). This is supported by the studies made in Sinai, El Arish and El Hassanah center in Egypt where it was found that ticks of $H$. dromedarii and other $H$. species are the most common species infesting camels. It was also found that these animals and ticks were positive in blood of tested animals and guts and heamolymph of identified ticks

\footnotetext{
${ }^{1}$ Department of Microbiology and Parasitology, College of

Veterinary Medicine and Animal Resource King Faisal University, B.P 1757, 31982 Al-Ahsa, Saudi Arabia

Received May25, 2008, Accepted June17, 2008
} 
(EL Kady, 1998; Mazyad and Khalaf, 2004). In this study ticks were collected from camels in order to open door for a major research project to study all areas of Najran Province to investigate all the parasites infesting camels, sheep, goats and cattle since all these animals are reared closed to each other in most parts of this province and may be infested by the same arthropods.

\section{MATERIALS AND METHODS}

Collection of samples and identification of the collected ticks was performed according to Hoogstral (1956), Soulsby (1986) and Zeleke and Bekele (2004).

\section{1-Tick Collection}

Adult ticks were collected from the camels reared in camps in four areas. These are Najran city, Al-) Morratah Vally (5 Km south), Khibash ( $70 \mathrm{Km}$ east and Habbonah ( $100 \mathrm{Km}$ north ). Although these camps contain a moderate number of camels only one camp from each place was selected. Every selected camp contains 100 camels. Camels were examined every month during the period of study, started from January until December 2005. Ticks were collected from 400 camels which we were assured that they would stay for the study period. Collected ticks were put in plastic vials with Isopropyl Alcohol for disinfection and fixing the samples .Samples collected form each camp were put alone. After that the ticks were counted and then prepared for identification.

\section{2-Tick identification}

Each tick was examined under stereomicroscope for identification. This was performed according to the keys of hard ticks mentioned by Hoogstraal (1956) ,Hoogsraal et. al. ( 1981) and Soulsby (1986).

\section{RESULTS}

Atotal of 22000 ticks were collected from the camels and the ground during the monitoring period. Ten species of ticks were identified. These are Hyalomma $a$. anatolicum, $H$. a. excavatum, $H$. dromedari, $H$. impeltatum, $H$. schulzei, $H$. erythraeum, $H$. marginatum rufipes, $H$. truncatum, Amblyomma $t$. gema and A. $t$. varigatum. Hyalomma species $(71 \%)$ were the most abundant species encountered; these were followed by Amblyomma species (29\%). It was found that the number of ticks varied every month and the maximum number was seen in December (2400 ticks) while the lowest number was seen in May and June (see table 1 and fig. 1). However, Amblyomma species were seen in very small numbers with samples from Habbonah comparing with those collected from other studied areas (See table 2 and fig. 2) during the period March August 2005.

\section{Table1. Monthly number of ticks collected from all the study areas of Najran Province during the study period Months No. of ticks}

\begin{tabular}{lccc} 
& Hyalomma & Amblyomma & \\
\cline { 2 - 4 } January & 2500 & 800 & 15 \\
February & 1820 & 600 & 8 \\
Marsh & 1260 & 500 & 6 \\
April & 860 & 460 & 3 \\
May & 400 & 140 & 3 \\
June & 530 & 120 & 2 \\
July & 340 & 110 & 2 \\
August & 360 & 140 & 10 \\
September & 1500 & 750 & 11 \\
October & 1620 & 810 & 13 \\
November & 2000 & 860 & 16 \\
December & 2400 & 1120 & $\mathbf{1 0 0}$ \\
\hline Total & $\mathbf{1 5 5 9 0 ( 7 1 \% )}$ & $\mathbf{6 4 1 0}(\mathbf{2 9 \%})$ & \\
\hline
\end{tabular}




\section{Table 2. Total number of tick species collected from each study area of Najran Province} during the study period

The number of ticks in the four studied areas

\begin{tabular}{lcccc}
\cline { 2 - 5 } Tick species & Najran City & Al-Maratah & Khibbash & Habbonah \\
\hline H a. anatolicum & 600 & 560 & 500 & 850 \\
H. a. excavatum & 450 & 480 & 450 & 800 \\
H. dromedari & 1000 & 1200 & 800 & 2300 \\
H. impeltatum & 250 & 230 & 300 & 300 \\
H. schulzei & 350 & 280 & 300 & 340 \\
H. erythraeum & 400 & 510 & 320 & 310 \\
H. m. rufipes & 300 & 200 & 210 & 200 \\
H. truncatum & 250 & 150 & 300 & 150 \\
A $t$. gema & 200 & 500 & 550 & 30 \\
A. $t$. varigatum & 1800 & 1700 & 1500 & 80 \\
Total & 5600 & 5810 & 5230 & 5360 \\
\hline \% & $\mathbf{2 5 . 4 \%}$ & $\mathbf{2 6 . 4 \%}$ & $\mathbf{2 3 . 8 \%}$ & $\mathbf{2 4 . 4 \%}$ \\
\hline
\end{tabular}

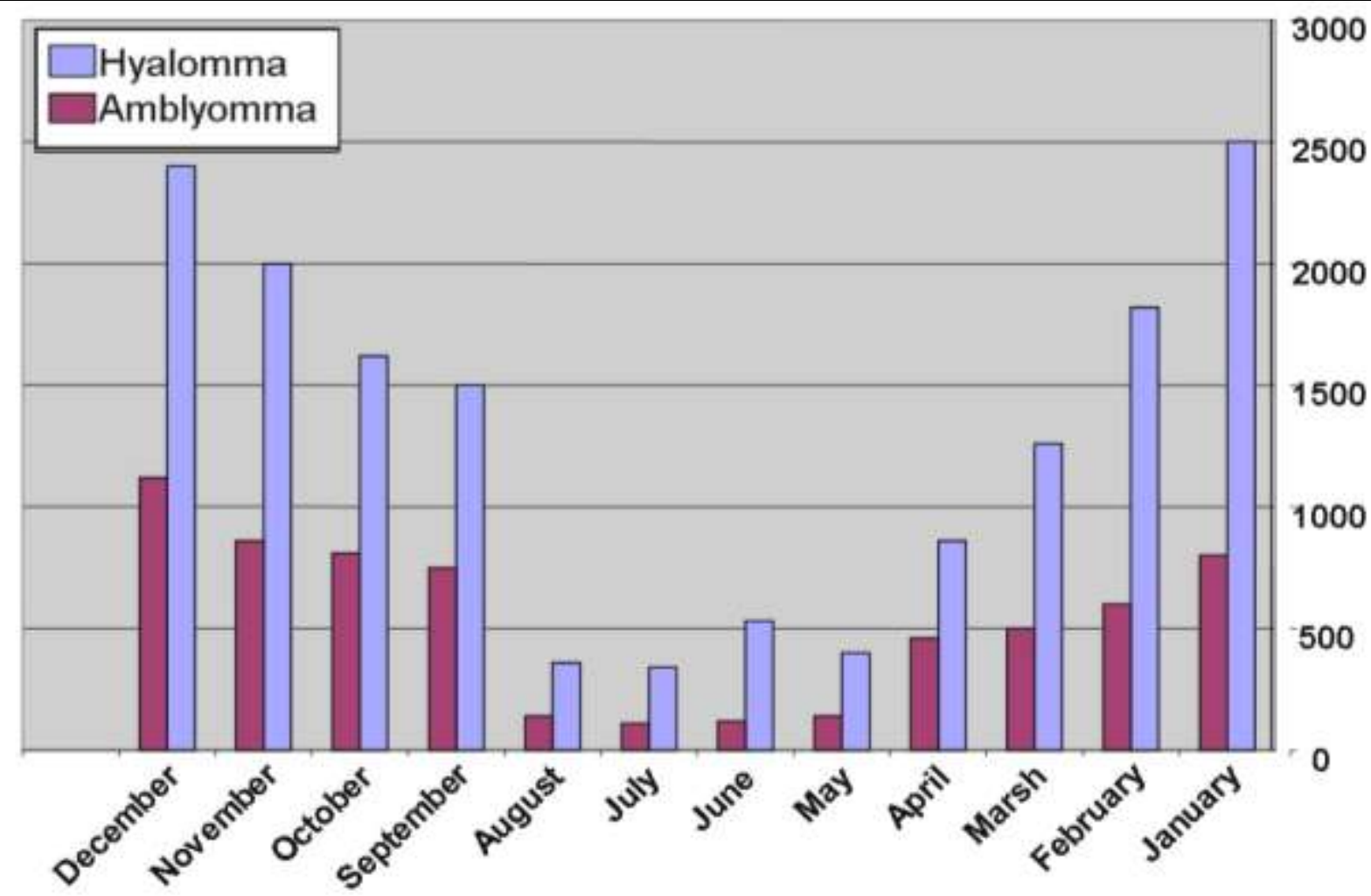

Figure1. The monthly variation of the collected tick numbers during the study period 




Figure2. The distribution of collected tick species in the four studied areas in Najran Province during the study period

\section{DISCUSSION}

An attempt was made to assess the seasonal population changes in the species of ticks on the camels in relation to rainfall and the environmental temperature. The most common adult ticks found on the camels belonged to two genera, namely Hyalomma (71\%), Amblyomma (29\%).These species are Hyalomma anatolicum anatolicum, $H$. a. excavatum, $H$. dromedari , H. impeltatum, $H$. schulzei, $H$. erythraeum, $H$. marginatum rufipes, $H$. truncatum, Amblyomma t. gema and A. t. varigatum . Comparing this result with that of Gupta and Kumar (1994) where they indicated that the most abundant species of ticks on Indian dromedaries was Hyalomma dromedarii (90\%) we can predict that the semi rainy climate of most Najran areas which are closed to the mountain borders of Yemen are very good habitats of most hard tick species including $H$. dromedarii and A. t.varigatum since they are continuous of Ethiopian fauna (Hoogstraal et. al., 1981). This is very clear in the results of tick number the studied area of Habbonah where Amblyomma t. gema and A. $t$. varigatum were seen in very small numbers ( see table 2 and fig. 2 ).This is because Habbonah is about $100 \mathrm{Km}$ from the mountainous borders and it has avery harsh dry desert ordinary climate ,however Najran City and the other three studied areas are aproximatly closed to the mountains and the running water vallies. For this reason they have moderate numbers of Amblyomma t. gema and $A$. t. varigatum ticks although they have $H$. dromedarii and other Hyalomma species . In fact $H$. dromedarii are the most abundant tick species in arid areas as they are well adapted to harsh environmental conditions (Morel, 1989). However the Rhipicephalus species are relatively restricted to forest, highland and semi-arid areas or certain rainfall conditions (Hoogstral, 1956). The arid climate of the present study area may be more favorable to $H$. dromedarii than to the other species. It was seen that the frequent contact between camels and cattle might have also contributed to the abundance of Rhipicephalus and Amblyomma species (Schwartz and Dioli, 1992).

Ticks were found on the camels throughout the monitoring period, although higher loads of ticks were observed during rainy months than during dry months. Even a small amount of rain may cause an increment in tick load. As well as the rainfall, the monthly maximum and minimum environmental temperatures appeared to affect the tick load. Although it was difficult to isolate the effect of temperature from that of rainfall, greater loads of ticks per camel were observed during the periods with lower maximum and higher minimum temperatures. Njanja (1991), Gupta and Kumar (1994) and Mushi et al. (1997) reported similar findings. The reason for the higher load of ticks during the rainy season may be the high humidity and lower temperature range, which facilitate the growth and survival of ticks at 
all their different life stages -egg, larva, nymph and adult (Hoogstral, 1956).

The overall result indicated that only a few species of ticks are commonly found on camels, with a marked seasonality in abundance. This suggests that, to be effective, tick control measures for camels should concentrate on the dominant tick species and their season of abundance. Strategic application of acaricide, especially at the beginning of wet months might minimize the burden of ticks on the camels. Further studies on the effect of these species of ticks on the productivity of camels, and determination of the minimum load that affects productivity must be performed in a major research project covering all the area of Northern Provinces of the Kingdom.

\section{ACKNOWLEDGEMENT}

Thanks are due to Dr S M Al-Nomais for his support during this study. Also thanks to the camel owners at the studied areas especially Mr. Momammed S Al-Nomais and Mr. Hammad S Al-Nomais and the other owners for their invaluable cooperation during the study period.

\section{RE FERENCES}

Al- Zubaidy, A. J. (1995): The Arabian Camel, Rearing and Pathology of camels (Arabic textbook), All Prints Distributors and Publishers, Beirut, Lebanon.

Al-Khalifa, M. S., Khalil, G. M. and Diab, F. M., (2007 ) : A Tow Years Study of Ticks infesting Goats and Sheep in Abha, Saudi Arabia . Saudi J. Biol. Sci, 14 , 83-91.

Banaja , A. A. and Ghandur ( 1994 ) : A review of Parasites of Camels ( Camelus dromedarius ) in Saudi Arabia. J K A $\mathrm{U}: \mathrm{Sci}, 6,75-86$

Banaja, A. A. , Madbouly, M. H. and Roshdy, M. A. ( 1980 ) : Ticks of Saudi Arabia 1. Ticks (Ixodidae) infesting imported and local breeds of domestic animals at Jeddah,4, Symp. Biol. Aspects ,Saudi Arabia Biol. Soc. ( Riyadh, March 1980 ), 339-346.

Banaja , A. A. and Roshdy, M. A. (1978) : Observation of ticks ( Acarina -Ixodidae) of Saudi Arabia . Bull. Fact. Sci ,K. A. U.,2 , 119-346 .

Dalgliesh, R.J., Jorgensen, W.K. and De Vos, A.J. (1990): Australian frozen vaccines for the control of babesiosis and anaplasmosis in cattle. A review. Tropical Animal Health and Production, 22, 44-52

ElKady, G. A. (1998): Protozoal parasites in tick species infesting camel in Sinai Peninsula. J. Egypt Soc. Parasitol.28:765-776
Global Arabic Encyclopedia (2008): www. mawsoah.net

Gupta, S.K. and Kumar, R. (1994). Ixodid ticks of camel in India and their control measures. International Journal of Animal Science, 9, 55-56

Hoogstral, H. (1956): African Ixodidea. Ticks of the Sudan, (US Navy, Washington, DC)

Hoogstraal , H. , Wassef, H. Y. and Buttiker, W. ( 1981) : Ticks ( Acarina ) of Saudi Arabia Fam. Argasdae , Ixodidae . Fauna Of Saudi Arabia,3 ,25-110.

Mazyad, S. A. and Khalaf, S. A. ( 2004 ): Studies on Theileria and Babesia infecting live and slaughtered animals in Al Arish and El Hasanah, North Sinai Governorate, Egypt . J. Egypt Soc. Parasitol. 32:601-610

Morel, P. (1989): Tick borne diseases of livestock in Africa. In: Manual of Tropical Veterinary Parasitology (Fisher S. and Say R.R, Eds.) CTA, Wallingford, 301-457

Mushi, E.Z., Isa, J.F., Proctor, J., Marchete, J.B. and Kapaata, R.W. (1997): Seasonal fluctuation of Ixodid ticks on a herd of indigenous goats at Oadi, Kgatleng District of Botswana. Tropical Animal Health and Production, 29, 29-30

Njanja, J.C. (1991): Productivity of Small Stock and Camels Under the Turkana Pastoral Livestock Production System in Central Turkana, TREMU Report No. E-1, (Turkana Resource Evaluation Monitoring Unit (TREMU), UNESCO, Nairobi, Kenya)

Schwartz, H.J. and Dioli, M. (1992): The One Humped Camel in Eastern Africa. A Pictorial Guide to Health Care and Management, (Verlag Josef Margraf, Berlin, Germany)

Soulsby, E. J. L. (1986): Helminths, Arthropods and Protozoa of Domesticated Animals, 7th Edition,Bailliere Tindall.

Urquhart, G.M., Armour J., Duncan J.L., Dunn A, M. and Jennings F.W. (1987) Veterinary Parasitology, $1^{\text {st }}$ Ed., Longman Scientific \& Technical, UK.

Walker A. (1994): Arthropods of humans and domestic animals, $1^{\text {st }}$ Ed, Chapman\& Hall .

Zeleke, M. and Bekele, T. (2004): Species of ticks on camels and their seasonal population dynamics in Eastern Ethiopia. Tropical Animal Health and Production, 36, 225-231 


\section{الملخص العربي \\ التعرف على أنواع القراد الجحامد التي تصيب الإبل العربية بمنطقة نجران بالمملكة \\ العربية السعودية ووفرتا الموسمية \\ مُحَّمَ حسين عبدلى}

Hyalomma anatolicum anatolicum, $H$. a. excavatum , H. dromedari, $H$. impeltatum, $H$. schulzei, $H$. erythraeum, H. marginatum rufipes, H. truncatum, Amblyomma t. gema and A. t. varigatum

وقد لوحظ في الدراسة أن تعداد القراد من النوعين الأخيرين متوفر

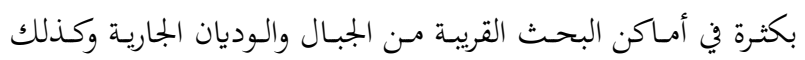

الحمدود الجبلية اليمنية ويقل في الأماكن التي تبعد عن الجبال والوديان

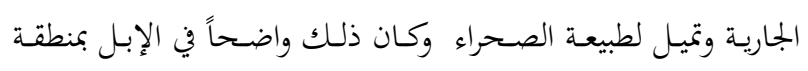

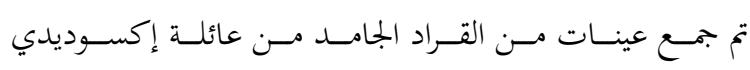$$
\text { Ixodidae }
$$

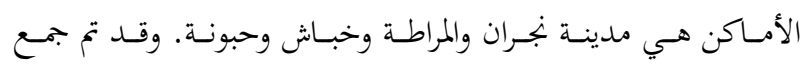

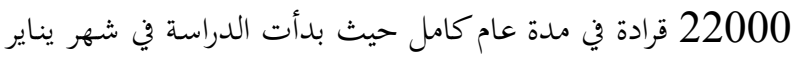

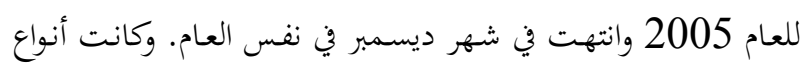

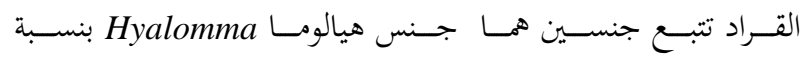

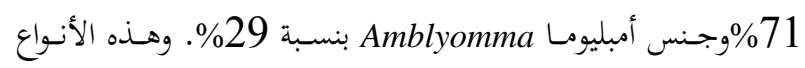


